\title{
Formulating the Strength Factor $\alpha$ for Improved Predictability of Radiation Hardening
}

L. Tan ${ }^{*}$, J.T. Busby

Oak Ridge National Laboratory, Oak Ridge, TN 37831, USA

* Corresponding author: One Bethel Valley Road, P.O. Box 2008, MS-6136, Oak Ridge, TN

37831; Phone: +1-865-574-4628; E-mail: tanl@ornl.gov (L. Tan)

\begin{abstract}
Analytical equations were developed to calculate the strength factors of precipitates, Frank loops, and cavities in austenitic alloys, which strongly depend on barrier type, size, geometry and density, as well as temperature. Calculated strength factors were successfully used to estimate radiation hardening using the broadly employed dispersed barrier-hardening model, leading to good agreement with experimentally measured hardening in neutron-irradiated type 304 and 316 stainless steel variants. The formulated strength factor provides a route for more reliable hardening predictions and can be easily incorporated into component simulations and design. Keywords: defects; TEM; stainless steels; strengthening
\end{abstract}

\section{Introduction}

Life extension of existing nuclear power plants is a sustainable energy solution to meet electricity demand, reduce greenhouse gas emissions, and ensure energy supply security and grid reliability. Radiation damage of reactor structural materials is one of the major aging phenomena that are unavoidable during life extension. Zinkle et al. [1] summarized five radiation damage threats to structural materials performance according to irradiation temperature and displacements per atom (dpa). Radiation hardening was identified as one of the main threats. 
Radiation hardening is primarily attributable to the agglomeration of radiation-produced point defects into extended defects, such as dislocation loops, stacking fault tetrahedral (only in face-centered cubic (fcc) metals), cavities, and precipitation of new phases [2], serving as obstacles to dislocation motion in metals and alloys. A dispersed barrier-hardening model has been broadly used to estimate obstacle-induced changes in yield strength $\left(\Delta \sigma_{y}\right)$, given as [3]

$$
\Delta \sigma_{y}=M \alpha \mu b / \lambda \approx M \alpha \mu b \sqrt{N d}
$$

where $M$ is the Taylor factor (3.06 for fcc polycrystals [4]), $\alpha$ the strength factor, $\mu$ the shear modulus of the matrix, $b$ the magnitude of the Burgers vector of the moving dislocation, and $\lambda$ the inter-obstacle spacing (a function of the number density $N$ and size $d$ of discrete obstacles). Among these parameters, only the strength factor $\alpha$ cannot be directly measured from experiments, resulting in uncertainties in the model. Lucas [5] summarized the reported $\alpha$ values of different types of defects and categorized them into three groups: 1) weak barriers such as small bubbles/loops and dislocations with $\alpha<0.25,2$ ) intermediate barriers such as Frank loops and small precipitates with $0.33<\alpha<0.45$, and 3) strong barriers such as voids and large precipitates with $\alpha \approx 1$ obstacles. An increase of bout $36 \%$ in $\Delta \sigma_{\mathrm{y}}$ would occur for small precipitates if $\alpha=0.45$ was chosen, compared with $\alpha=0.33$. Additionally, there is no defined size range for small precipitates. This classification provides preliminary guidance for selecting initial $\alpha$ values that are usually adjusted subsequently to obtain a best fit when they are compared with experimental hardening data. This scenario constrains the predictability of the dispersed barrier-hardening model, as it is not directly based on a physical phenomenon. The purpose of this paper is to formulate analytical equations of $\alpha$ for different types of defects typically observed in austenitic stainless steels, leading to improved predictability of radiation hardening. 
By changes in appropriate parameters, the deduced analytical equations are applicable beyond austenitic stainless steels.

\section{Calculation of strength factor $\alpha$}

\subsection{Precipitates}

Two mechanisms are considered for precipitate strengthening during dislocation-precipitate interaction in metals and alloys. One is a classical Orowan mechanism with dislocation bowing around incoherent, semi-coherent, or large coherent obstacles. The other is dislocation shearing of small coherent precipitates. The accepted equation with the least simplification of the classical Orowan mechanism is given as [6]:

$$
\Delta \sigma=\frac{M B}{\lambda} \ln \left(\frac{\bar{d}}{r_{0}}\right)
$$

where $B=\frac{0.85 \mu b}{2 \pi(1-v)^{1 / 2}}$ for isotropic material with $v$ for Poisson's ratio, $r_{0}=$ dislocation core radius (in the range $b$ to $4 b[7]$ ), and $\bar{d}=$ the geometry-corrected effective diameter of the obstacles. Kelly [8] elaborated the effect of particle shape $(\bar{d})$ on dispersion hardening with analytical equations summarized in Table 1. Depending on the shapes of the obstacles, Eq. ( 2 ) can be rewritten based on defect geometry, where:

Spherical

$$
\Delta \sigma_{S P}=\frac{0.135 M \mu b \sqrt{N d}}{(1-v)^{1 / 2}(1-0.816 d \sqrt{N d})} \ln \left(\frac{0.816 d}{r_{0}}\right)
$$

Rod-shaped

$$
\Delta \sigma_{R P}=\frac{0.0957 M \mu b \sqrt{N l}}{(1-v)^{1 / 2}(1-\delta \sqrt{N l})} \ln \left(\frac{1.414 \delta}{r_{0}}\right)
$$

Aligned thinplate-shaped

$$
\Delta \sigma_{P P}=\frac{0.271 M \mu b A}{(1-v)^{1 / 2}(16-\pi t A)} \ln \left(\frac{0.637 D}{r_{0}}\right)
$$

with $A=\sqrt{16 \pi N D}+4 N D^{2}-\pi^{2} N D t$. The variables in the equations are defined in Table 1 . 
Comparing the Eqs. ( 3-5 ) with ( 1 ), the strength factor can be deduced as

Spherical

$$
\alpha_{S P}=\frac{0.135}{(1-v)^{1 / 2}(1-0.816 d \sqrt{N d})} \ln \left(\frac{0.816 d}{r_{0}}\right)
$$

Rod-shaped

$$
\alpha_{R P}=\frac{0.0957 \sqrt{l / \delta}}{(1-v)^{1 / 2}(1-\delta \sqrt{N l})} \ln \left(\frac{1.414 \delta}{r_{0}}\right)
$$

Aligned thinplate-shaped

$$
\alpha_{P P}=\frac{0.271 A}{(1-v)^{1 / 2} \sqrt{N D}(16-\pi t A)} \ln \left(\frac{0.637 D}{r_{0}}\right)
$$

Compared with the Orowan dislocation bowing mechanism, the changes in yield strength by shearing of small coherent obstacles $\left(\Delta \sigma_{\mathrm{c}}\right)$ originate from different aspects, such as order strengthening $\left(\Delta \sigma_{1}\right)$, coherency strengthening $\left(\Delta \sigma_{2}\right)$, modulus mismatch strengthening $\left(\Delta \sigma_{3}\right)$, stacking-fault strengthening, and chemical strengthening in a descending order of contribution magnitude [9]. The yield strength change in metals and alloys can be estimated by $[9,10]$ :

Coherent $\quad \Delta \sigma_{C P}=\frac{M \gamma_{c p} \bar{d}}{b \lambda}+M \chi \mu \varepsilon^{1.5} \sqrt{\frac{\bar{d} f}{b}}+0.0055 M(\Delta \mu)^{1.5} \sqrt{\frac{2 f}{\mu}}\left(\frac{\bar{d}}{2 b}\right)^{\frac{3 m}{2}-1}$

where $\gamma_{\mathrm{cp}}\left(\mathrm{J} / \mathrm{m}^{2}\right)=$ the interfacial energy due to disordering of the specific coherent spherical obstacles, $\chi=$ a constant differing from one theory to the other (varying between 2 and 3, e.g., $\chi$ $=2.6), \varepsilon \approx(2 / 3)(\Delta a / a)$ the constrained lattice parameter $(a)$ mismatch between obstacle and matrix, $m=$ a constant $(=0.85)$, and $\Delta \mu=$ the shear modulus mismatch between obstacle and matrix. According to the parameters defined above and comparing Eq. ( 9 ) with Eq. ( 1 ), the strength factor of small coherent spherical obstacles can be expressed as

Coherent $\quad \alpha_{C P}=\frac{0.816 \gamma_{c p} d}{\mu b^{2}(1-0.816 d \sqrt{N d})}+1.7\left(\frac{d}{b}\right)^{1.5} \varepsilon^{1.5}+0.0054\left(\frac{d}{b}\right)^{0.275}\left(\frac{\Delta \mu}{\mu}\right)^{1.5}$ 


\subsection{Frank loops}

It has been found that three forms of dislocations, i.e., black spots, Frank loops, and dislocation networks, result in radiation hardening; each is dominant in a different temperature regime. Black spots dominate at low temperatures $\left(<\sim 200^{\circ} \mathrm{C}\right)$, whereas dislocation networks become dominant above $400-450^{\circ} \mathrm{C}$ in austenitic stainless steels [10]. Frank loops dominate in the intermediate temperature regime $\left(\sim 200-\sim 400^{\circ} \mathrm{C}\right)$ in austenitic stainless steels [10], which are primarily considered in light water reactor conditions. Frank loops are generated by vacancies or interstitials coalescing as platelets between two adjacent $\{111\}$ close-paced planes in fcc materials, which can be considered as aligned ultra-thin plate-shaped obstacles with measured diameter $(D)$ and thickness $(t=0.207 \mathrm{~nm})$ as the interspacing of $\{111\}$ planes. Thus, the strengthening contribution of Frank loops can be estimated using Eq. ( 5 ) and their strength factor using Eq. ( 8 ).

\subsection{Cavities}

Scattergood and Bacon [10,11] developed the cavity hardening by assuming spherical geometry with a zero surface energy parameter in austenitic stainless steels, which can be rewritten as

$$
\Delta \sigma_{C}=\frac{2.83 M B}{\lambda} \ln \left(\frac{\bar{d}}{r_{0}} \frac{\lambda}{3.3 L_{S}}\right)
$$

with $L_{S}$ denoting the center-to-center spacing of spherical cavities (Table 1). Using the parameters described above, the strength factor of cavities can be derived as

$$
\alpha_{C}=\frac{0.383}{(1-v)^{1 / 2}(1-0.816 d \sqrt{N d})} \ln \left[\frac{0.247 d}{r_{0}}(1-0.816 d \sqrt{N d})\right]
$$




\section{Experimental}

AISI 304 and 316 stainless steels are common reactor core structural materials. A set of type 304 and 316 variants was studied in this work to explore their radiation responses. Many of the alloys had been modified from a high-purity version of 304 stainless steel (alloy E) by altering the composition of specific alloying elements, e.g., alloy $\mathrm{F}$ by reducing carbon and alloys $\mathrm{G}, \mathrm{K}$, $\mathrm{L}$, and $\mathrm{P}$ by adding $\mathrm{Mo}, \mathrm{Ni},(\mathrm{Ni}+\mathrm{Cr})$, and $(\mathrm{Mo}+\mathrm{Hf})$, respectively. Additionally, two industrial heats of 304 (alloys A and SW) and one industrial heat of 316 (alloy B) were investigated together. Alloys $\mathrm{G}$ and $\mathrm{P}$ also can be considered as the variants of type 316 steels due to their Mo additions. The use of multiple alloys with varying alloy compositions allows for validation of the analytical strength factors and determination of any composition dependence. The detailed alloy compositions are listed in Table 2. Different levels of cold work were applied to alloys B, E, F, and G. The other alloys are in an annealed condition, e.g., $1050^{\circ} \mathrm{C}$ for $30 \mathrm{~min}$ followed by water quenching. Samples of the alloys had been irradiated in the BOR-60 reactor at $\sim 320^{\circ} \mathrm{C}$ for up to $11.8 \mathrm{dpa}$ at a displacement rate of $\sim 8 \times 10^{-7} \mathrm{dpa} / \mathrm{s}$. The details of the irradiation experiment can be found in Ref. [12].

Irradiated microstructures were characterized using transmission electron microscopy (TEM) in both conventional and scanning modes on a FEI CM200 field-emission-gun TEM/scanning TEM equipped with an EDAX energy dispersive X-ray spectroscopy (EDS) detector. TEM discs of $3 \mathrm{~mm}$ diameter were extracted from the flat tab section of the irradiated tensile samples $(2 \mathrm{~mm}$ diameter gauge section [12]) and mechanically thinned to less than $\sim 100 \mu \mathrm{m}$ thickness. All TEM specimens were electropolished at $-12^{\circ} \mathrm{C}$ in a methanol:sulfuric $(7: 1)$ solution using a Struers Tenupol polishing unit. Specimen thickness was estimated using the convergent beam electron diffraction technique [13]. 


\section{Results and discussions}

\subsection{Experimental observations}

Radiation-induced Frank loops, cavities, and precipitates were observed in the alloy samples. Their typical microstructures are illustrated in Fig. 1. Using the rel-rod imaging technique $[14,15]$, edge-on Frank loops are revealed as aligned white streaks in the dark-field (DF) TEM image, e.g., Fig. 1a for sample BS13, which was taken using the arrow-pointed streak reflection

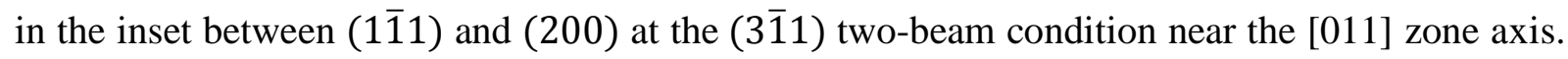
Loop size was measured using the length of the white streaks, and loop density was estimated by the volumetric loop numbers times a factor of 4 due to the visibility criteria of the possible loop variants at this beam condition. The size and density have been statistically averaged from at least 300 loops and at least three images at different locations of each alloy sample. Figure $1 \mathrm{~b}$ exhibits some cavities pointed out with arrows in the bright-field (BF) image of sample KS13, which was taken at under-focus to reveal the cavities with a bright center enclosed by a dark ring. The through-focus technique was employed during TEM imaging to confirm the cavities. A few types of radiation-induced precipitates have been observed in the alloy samples [14], which were identified by their diffraction patterns coupled with EDS results and alloy thermodynamics of the respective alloys. The DF image in Fig. 1c shows an example of G-phase or $\mathrm{M}_{23} \mathrm{C}_{6}$ as bright spherical particles in sample ES13, which was taken using the arrow-pointed reflection $\left(1 / 3 \mathrm{~g}_{022}\right)$ at the $(0 \overline{2} 2)$ two-beam condition near the [011] zone axis. The two phases are difficult to differentiate from diffraction patterns because they have the same space group $(\mathrm{Fm}-3 \mathrm{~m})$ and similar lattice parameters. An unknown type of precipitate was observed in many of the alloy samples, e.g., the DF image in Fig. 1d captured in sample FS13 using the diffraction 
ring pointed to by an arrow. The diffraction ring pattern suggests the random orientation of the precipitates in the austenite matrix and reveals a lattice parameter of $0.2498 \mathrm{~nm}$, consistent with the $\alpha^{\prime}$-phase. Additionally, $\gamma^{\prime}$-type precipitates (not shown here) were observed in samples of alloy B. The densities and average sizes of the loops, cavities, and precipitates have been statistically characterized for the samples and are listed in Table 3. The detailed microstructures of the alloy samples are to be reported separately.

\subsection{Strength factor calculation}

With the parameters of $v=0.29[16], b=0.253 \mathrm{~nm}(b=a / \sqrt{2}$ of fcc, where $a$ is the lattice parameter), and $r_{0}=b$ [7] for type 304 and 316 at room temperature, the strength factors for radiation-induced precipitates, Frank loops, and cavities can be calculated according to Eqs. ( 6 ), ( 8 ), and ( 12 ) by substituting the experimentally measured number density and average size. Rod-shaped and aligned thin-plate-shaped precipitates were not observed in the samples and thus are not evaluated here. To calculate the strength factor of small coherent precipitates, e.g., $\gamma^{\prime}-$ phase in BS13 and BS16 samples, using Eq. ( 10 ), the $\gamma_{\mathrm{cp}}, \Delta \mu$, and $\varepsilon$ were estimated to be 0.102 $\mathrm{J} / \mathrm{m}^{2}$ [17], 18.9 GPa [18], and 0.013 [19], respectively at room temperature. The calculated room temperature strength factor as a function of obstacle size $(d)$ is plotted in Fig. 2 with solid and open symbols denoting the results calculated from the data generated in this work and the literature, respectively. The literature data for the sizes and densities of loops, precipitates, and cavities were obtained from type 304 and 316 variants neutron-irradiated at $275-375^{\circ} \mathrm{C}$ $[20,21,22,23,24,25,26,27,28,29,30,31]$. Similar to the observations in this work, the majority of the reported data are loops, with some precipitates and limited numbers of cavities. The experimental data cover 0.6 to 120 dpa with small variations in displacement rates. The effects 
of dose and dose rate on $\alpha$ are manifested through the well-documented dose- and dose-ratedependent evolution of obstacle size and density. For obstacles greater than $\sim 2 \mathrm{~nm}$, ultrafine coherent precipitates and cavities have the smallest and greatest $\alpha$, respectively. Spherical precipitates have moderate $\alpha$, slightly greater than or comparable to that of Frank loops. Some of the calculated results are consistent with the three proposed regimes [5] shown with shaded bands in Fig. 2. However, a significant portion of the data exists outside of the three regimes.

The strength factors of spherical precipitates $\left(\alpha_{\mathrm{P}}\right)$, Frank loops $\left(\alpha_{\mathrm{L}}\right)$, and cavities $\left(\alpha_{\mathrm{C}}\right)$ calculated from the experimental data from this work and literature reports are well-fitted by a function of $\alpha=\mathrm{k}_{1} \ln \left(\mathrm{k}_{2} d\right)$ using least squares. This function has a consistent format as the Eqs. ( 6 ), ( 8 ), and ( 12 ), where $\mathrm{k}_{1}$ and $\mathrm{k}_{2}$ are fitting parameters depending on obstacle type, geometry, size and density, Poisson's ratio, and dislocation core radius of the alloy. The strength factor of $\gamma^{\prime}$ cannot be fit by this function due to the different format in Eq. (10). The fitting results are listed in Table 4. The fitted obstacle volume fraction $(f)$ and dislocation core radius $\left(r_{0}\right)$ were easily deducible from the fitting parameters $\mathrm{k}_{1}$ and $\mathrm{k}_{2}$, respectively, for spherical precipitates and cavities. However, the volume fraction of the Frank loops could not be deduced due to the complexity of Eq. ( 8). The fitting results suggest $\sim 0.043$ vol.\% cavities (or swelling) and $\sim 0.611$ vol.\% spherical precipitates (primarily G-phase) in the irradiated type 304 and 316 variants. The fitted core radii of cavities, spherical precipitates, and Frank loops are $\sim 1.02 b$, $\sim 1.19 b$, and $\sim 1.77 b$, respectively. Compared with the initial calculation input of $r_{0}=b$ for the obstacles, the excellent fit quality of $\alpha_{\mathrm{C}}\left(\mathrm{R}^{2}=0.999\right)$ of the available data suggests that the dose (1-73 dpa), dose rate, irradiation temperature $\left(290-375^{\circ} \mathrm{C}\right)$, and alloy variations did not result in significant deviations from the fitted average $\sim 0.043 \mathrm{vol} . \%$ in the experimental measurements (i.e., size and density) of cavities in this work and literature reports. The good fit quality of $\alpha_{\mathrm{P}}$ 
$\left(\mathrm{R}^{2}=0.974\right)$ suggests that the dose $(5.5-120 \mathrm{dpa})$, dose rate, irradiation temperature (320$343^{\circ} \mathrm{C}$ ), and alloy variations resulted in some deviations from the fitted average 0.611 vol.\% in the measured volume fractions of spherical precipitates. In contrast, the calculated $\alpha_{\mathrm{L}}$ has a large scattering among the literature data and this work, resulting in a low fit quality $\left(\mathrm{R}^{2}=0.785\right)$. The large deviation of $\alpha_{\mathrm{L}}$ suggests the prominent effects of dose (0.6-120 dpa), dose rate, irradiation temperature $\left(275-375^{\circ} \mathrm{C}\right)$, and alloy variations on loop size and density. Additionally, consistent and accurate size and density characterization is difficult to achieve for Frank loops, compared with cavities and precipitates, due to the nature of Frank loops and the rel-rod imaging technique. Frank loops have a significantly larger size variation than precipitates, as shown in Fig. 1a as compared with Fig. 1c. Large loops may escape the thin foil during TEM specimen thinning and glissile loops may escape to the free surfaces of the TEM specimens, reducing loop density and altering the average loop size. The difficulty in setting the correct brightness threshold during image analysis of Frank loops resulted in a variable cutoff for small loops, which reduced loop density and increased average loop size. The thin foil specimen thickness used to calculate density was either measured by different TEM techniques or assumed to be $100 \mathrm{~nm}$ among the literature data, which increased the uncertainty of the density.

According to the fitting results listed in Table 4, the critical sizes (i.e., at $\alpha=0$ ) for spherical precipitates, Frank loops, and cavities at room temperature are calculated to be about 0.370 , 0.705 , and $1.066 \mathrm{~nm}$, respectively, above which values these types of obstacles are expected to exhibit a strengthening effect $(\alpha>0)$ in type 304 and 316 variants. The critical size of spherical precipitates is close to a unit cell of the alloy, whereas the critical size of Frank loops is about 3 atom spacings on $\{111\}$ planes. The critical size of cavities is consistent with the observations of Simons et al. [10] and atomic-scale simulations [32] that indicate cavities contributing to 
hardening when their sizes are larger than $\sim 1 \mathrm{~nm}$; the contribution becomes significant when their sizes are larger than $\sim 4 \mathrm{~nm}$. Smaller cavities not only cannot significantly lower the dislocation energy but also can be bypassed by cross slip or climb during slow deformation processes.

\subsection{Radiation hardening calculation}

With the calculated $\alpha$, radiation hardening induced by each type of obstacle can be easily calculated using Equ. ( 1 ) with $\mu$ and $v$ taken from [33], e.g., 78.45 and $77.47 \mathrm{GPa}$ at room temperature and 68.25 and $66.29 \mathrm{GPa}$ at $330^{\circ} \mathrm{C}$ for type 304 and 316, respectively, and 0.31 and 0.32 Poisson's ratio for type 304 and 316 , respectively, at $330^{\circ} \mathrm{C}$. Alloying elements and cold work have some effects on $\mu$, but they are not considered here because their effects may not be significant, e.g., $~ 5$ GPa decrease in $\mu$ after about 20-60\% cold deformation of type 304 stainless steels [34]. As suggested in [3,35], radiation hardening of the alloys was calculated using the root-sum-square law, $\Delta \sigma_{y}=\sqrt{\sum_{i}\left(\Delta \sigma_{y, i}\right)^{2}}$, for obstacles with similar strengths and in combination with the linear law, $\Delta \sigma_{y}=\sum_{i} \Delta \sigma_{y, i}$, when considering the obstacles with dissimilar strengths, e.g., the coherent precipitates and the largest cavities in Fig. 2.

The comparison between the calculated and measured hardening results at room temperature and at $330^{\circ} \mathrm{C}$ is plotted in Fig. 3. Some of the alloys' results are not plotted in the figure due to the unavailability of their experimental data for comparison. Frank loops exhibited a major contribution to the hardening. They also exerted the primary uncertainties over the final errors in Fig. 3 due to their large size variations. The measured hardening results at $330^{\circ} \mathrm{C}$ and room temperature, respectively, are literature data obtained by tensile testing [12] and retrieved from ball indentation testing; the ball indentation tests were conducted on the flat tabs of the tensile- 
tested samples using 1-mm-diameter tungsten carbide spherical indenters [36] due to the limited volume of the irradiated samples. The experimental measurement errors are not included in Fig. 3 because of the uncertainty regarding the propagation of errors resulting from the retrieval method from ball indentation at room temperature, and the limited numbers (one or two) of tensile testing samples per alloy at $330^{\circ} \mathrm{C}$. The calculated and measured results approximately follow the $y=x$ straight line, suggesting they are in good agreement considering the errors in the calculated results and the unknown degree of uncertainty of the experimental results. In contrast to the use of $r_{0}=b$ at room temperature, $r_{0}=2.5 b$ was used in the calculations to obtain acceptable consistency with the $330^{\circ} \mathrm{C}$ tensile data, suggesting the possible effect of temperature on $r_{0}$ and subsequent $\alpha$. The relative overestimation of the calculated data for alloys $\mathrm{B}, \mathrm{E}$, and $\mathrm{G}$ is likely attributable to an overestimation of $\mu$ due to the cold work applied to the alloys. Furthermore, the applied cold work may have been partially annealed out during the irradiation at $\sim 320^{\circ} \mathrm{C}$, leading to an underestimation of the measured hardening. Figure 3 indicates that the deduced calculations for $\alpha$ would provide a reliable hardening estimation and prediction. Further studies are necessary to verify their applicability to other alloy systems at various conditions.

\section{Conclusion}

A dispersed barrier-hardening model was broadly used to estimate obstacle-induced strengthening in austenitic alloys. Despite the available general guidance, it is still difficult to select a correct strength factor $(\alpha)$ in the model to obtain reliable estimations that are comparable to experimental data. This paper develops analytical equations of $\alpha$ and simplifies them in a form of $\alpha=\mathrm{k}_{1} \ln \left(\mathrm{k}_{2} d\right)$ for different types of barriers observed in type 304 and 316 variants that were neutron-irradiated to $0.6-120 \mathrm{dpa}$ at $275-375^{\circ} \mathrm{C}$. Analysis of the calculated $\alpha$ yielded a 
fitted average of $\sim 0.043$ vol.\% cavities (or swelling) and $\sim 0.611$ vol.\% spherical precipitates (primarily G-phase) in type 304 and 316 variants. The critical sizes of spherical precipitates, Frank loops, and cavities were estimated, above which these types of barriers should exhibit a measurable strengthening effect in type 304 and 416 variants. Strength factors were found to be strongly dependent on barrier type, size, geometry, and density, as well as temperature. With the formulated $\alpha$, the radiation hardening of type 304 and 316 variants was successfully predicted, using the dispersed barrier-hardening model, with good agreement with experimental results at room temperature and $330^{\circ} \mathrm{C}$.

\section{Acknowledgments}

This research was sponsored by the U.S. Department of Energy, Office of Nuclear Energy, Light Water Reactor Sustainability Program, under contract DE-AC05-00OR22725 with University of Tennessee-Battelle, LLC. The research was conducted as part of a user project supported by Oak Ridge National Laboratory's (ORNL) Center for Nanophase Materials Sciences, which is sponsored by the Scientific User Facilities Division, Office of Basic Energy

Sciences, US Department of Energy. The authors would like to thank Drs. Gary Was (Univ. of Michigan), Roger Stoller, Yury Osetskiy, Kevin Field and Xunxiang Hu (ORNL) for their reviews of this manuscript.

\section{References}

[1] S.J. Zinkle, J.T. Busby, Mater. Today 12 (2009) 12.

[2] F.A. Garner, Radiation damage in austenitic steels, in: F.J.M. Konings, T.R. Allen, R.E. Stoller, S. Yamanaka (Eds.), Comprehensive Nuclear Materials, Elsevier, The Netherlands, 2012.

[3] G.S. Was, Fundamentals of Radiation Materials Science, Springer-Verlag, Berlin, 2007.

[4] R.E. Stoller, S.J. Zinkle, J. Nucl. Mater. 283-287 (2000) 349.

[5] G.E. Lucas, J. Nucl. Mater. 206 (1993) 287. 
[6] P.B. Hirsch, F.J. Humphreys, Plastic deformation of two-phase alloys containing small nondeformable particles, in: A.S. Argon (Ed.), Physics of Strength and Plasticity, M. I. T. Press, 1969, pp.189.

[7] D. Hull, D.J. Bacon, Introduction to Dislocations, fifth ed., Elsevier, Oxford, 2011.

[8] P.M. Kelly, Scripta Metall. 6 (1972) 647.

[9] A.J. Ardell, Met. Trans. A 16 (1985) 2131.

[10] R.L. Simons, L.A. Hulbert, Correlation of yield strength with irradiation-induced microstructure in AISI type 316 stainless steel, in: F.A. Garner, J.S. Perrin (Eds.), Effects of Radiation on Materials: $12^{\text {th }}$ Int. Symp., ASTM STP 870, 1985, pp. 820-839.

[11] R.O. Scattergood, D.J. Bacon, Acta Metall. 30 (1982) 1665.

[12] CIR II program: description of the Boris 6 and 7 experiments in the BOR-60 fast breeder reactor, EPRI, Palo Alto, CA: 2005. 1011787.

[13] D.B. Williams, C.B. Carter, Transmission Electron Microscopy, second ed., Springer, New York, 2009.

[14] L. Tan, K.G. Field, M.N. Gussev, J.T. Busby, Microstructural evolution of type 304 variants and 316 stainless steel under neutron irradiation, 16 ${ }^{\text {th }}$ Int. Conf. on Environmental Degradation of Materials in Nuclear Power Systems-Water Reactors, Asheville, NC, US, August 11-15, 2013.

[15] L. Tan, J.T. Busby, H.J.M. Chichester, K. Sridharan, T.R. Allen, J. Nucl. Mater. 437 (2013) 70.

[16] H.M. Ledbetter, J. Mater. Sci. 20 (1985) 2923.

[17] R.O. Williams, Acta Metall. 5 (1957) 241.

[18] S.V. Prikhodko, D.G. Isaak, J.D. Carnes, S. Moser, Y. Ma, A.J. Ardell, Metall. Mater. Trans. A 34 (2003) 1863.

[19] A.B. Kamara, A.J. Ardell, C.N.J. Wagner, Metall. Mater. Trans. A 27 (1996) 2888.

[20] D.J. Edwards, E.P. Simonen, S.M. Bruemmer, J. Nucl. Mater. 317 (2003) 13.

[21] D.J. Edwards, E.P. Simonen, F.A. Garner, L.R. Greenwood, B.M. Oliver, S.M. Bruemmer, J. Nucl. Mater. 317 (2003) 32.

[22] D.J. Edwards, F.A. Garner, S.M. Bruemmer, Pal Efsing, J. Nucl. Mater. 384 (2009) 249.

[23] D.J. Edwards, A. Schemer-Kohrn, S. Bruemmer, Characterization of neutron-irradiated 300series stainless steels, EPRI, Palo Alto, CA: 2006. 1009896.

[24] D.J. Edwards, S.M. Bruemmer, Characterization of CIR II irradiated stainless steels, EPRI, Palo Alto, CA: 2008. EP-P19021/C9406.

[25] Y. Chen, O.K. Chopra, W.K. Soppet, W.J. Shack, Y. Yang, T. Allen, A.S. Rao, Cracking behavior and microstructure of austenitic stainless steels and alloy 690 irradiated in BOR-60 reactor, phase I, Argonne National Laboratory, ANL/09-32.

[26] Y. Yang, Y. Chen, Y. Huang, T. Allen, A. Rao, Irradiation microstructure of austenitic steels and cast steels irradiated in the BOR-60 reactor at $320^{\circ} \mathrm{C}$, in: J.T. Busby, G. Ilevbare, P.L. Andresen (Eds.), $15^{\text {th }}$ Int. Conf. on Environmental Degradation of Materials in Nuclear Power Systems-Water Reactors, John Wiley \& Sons, Inc., 2012, pp. 2137-2148.

[27] Y. Yang, T.R. Allen, Y. Chen, O.K. Chopra, Dose dependence of radiation hardening of austenitic steels in Bor-60 at PWR-relevant temperatures, $14^{\text {th }}$ Int. Conf. on Environmental Degradation of Materials in Nuclear Power Systems, Virginia Beach, VA, US, August 2327, 2009, pp. 1335-1340. 
[28] A.-É. Renault, C. Pokor, J. Garnier, J. Malaplate, Microstructure and grain boundary chemistry evolution in austenitic stainless steels irradiated in the BOR-60 reactor up to 120 dpa, ibid., pp. 1324-1334.

[29] C. Pokor, Y. Brechet, P. Dubuisson, J.-P. Massoud, A. Barbu, J. Nucl. Mater. 326 (2004) 19.

[30] K. Fukuya, K. Fuji, H. Nishioka, Y. Kitsunai, J. Nucl. Sci. Tech. 43 (2006) 159.

[31] Materials reliability program characterization of type 316 cold-worked stainless steel highly irradiated under PWR operating conditions (MRP-73), EPRI-1003525, August, 2002.

[32] Yu.N. Osetsky, D.J. Bacon, Phil. Mag. 90 (2010) 945.

[33] Austenitic chromium-nickel stainless steels - engineering properties at elevated temperatures, The International Nickel Company Inc., INCO2980, 1963.

[34] Y. Yamada (chief Ed.), Materials for Springs, Springer-Verlag Berlin Heidelberg 2007.

[35] G.R. Odette, G.E. Lucas, Radiation Effects of Defects in Solids 144 (1998) 189.

[36] M.N. Gussev, L. Tan, J.T. Busby, Analysis of irradiation-induced phase transformations under LWR relevant conditions, Oak Ridge National Laboratory, ORNL/LTR-2012/436. 


\section{TABLES}

Table 1. Parameters of different shaped obstacles used in Eq. (2).

\begin{tabular}{|c|c|c|c|c|c|}
\hline Obstacles & $\lambda$ & $L^{\mathrm{a}}$ & $f^{\mathrm{b}}$ & $\bar{d}$ & $\mathrm{P}$ \\
\hline Spherical $^{c}$ & $\lambda=L_{S}-\bar{d}_{S}$ & $L_{S}=\sqrt{\frac{\pi d^{2}}{6 f_{S}}}$ & $f_{S}=\frac{\pi}{6} d^{3} N$ & $\bar{d}_{S}=\sqrt{\frac{2}{3}} d$ & \\
\hline Rod-shaped & $\lambda=L_{R}-\bar{d}_{R}$ & $L_{R}=\sqrt{\frac{\pi \delta^{2}}{2 f_{R}}}$ & $f_{R}=\frac{\pi}{4} \delta^{2} l N$ & $\bar{d}_{R}=\sqrt{2} \delta$ & \\
\hline $\begin{array}{l}\text { Aligned thin- } \\
\text { plate-shaped }\end{array}$ & $\lambda=\frac{L_{P}}{1+P / L_{P}}-\bar{t}$ & $L_{P}=\sqrt{\frac{D t}{f_{P}}}$ & $f_{P}=\frac{\pi}{4} D^{2} t N$ & & $\begin{array}{l}P=\bar{D}-\bar{t} \\
=\frac{2 D}{\pi}-\frac{\pi t}{2}\end{array}$ \\
\hline
\end{tabular}

${ }^{a} L-$ obstacle center-to-center spacing.

${ }^{\mathrm{b}} f$ - obstacle volume fraction; $\delta$ - rod diameter; $l$ - rod length; $D$ - thin-plate diameter; $t$ - thin-plate thickness.

${ }^{\mathrm{c}}$ Not for small coherent particles, through which dislocations shear.

Table 2. Alloy compositions (wt.\%) and the investigated samples.

\begin{tabular}{cccccccccccccc}
\hline $\begin{array}{c}\text { Alloy } \\
\text { ID }\end{array}$ & Remark & $\mathrm{C}$ & $\mathrm{Mn}$ & $\mathrm{Si}$ & $\mathrm{Cr}$ & $\mathrm{Ni}$ & $\mathrm{Mo}$ & $\mathrm{Nb}$ & $\mathrm{Ti}$ & $\mathrm{Hf}$ & $\mathrm{P}$ & $\begin{array}{c}\text { Sample } \\
\text { ID }\end{array}$ & $\begin{array}{c}\text { Dose } \\
\text { (dpa) }\end{array}$ \\
\hline $\mathrm{A}$ & Ind. 304 & 0.023 & 1.82 & 0.56 & 19.95 & 10.8 & 0.53 & $<0.001$ & 0.02 & - & 0.023 & $\begin{array}{c}\text { AS13 } \\
\text { AS18 }\end{array}$ & $\begin{array}{c}5.5 \\
10.2\end{array}$ \\
\hline $\mathrm{SW}$ & Ind. 304 & 0.022 & 1.07 & 0.24 & 18.42 & 10.45 & - & - & - & - & 0.015 & $\mathrm{SW} 37$ & 4.4 \\
\hline $\mathrm{E}$ & HP304 & 0.021 & 0.94 & 0.04 & 18.76 & 12.37 & 0.04 & - & 0.01 & - & $<0.01$ & $\mathrm{ES} 13$ & 11.8 \\
\hline $\mathrm{F}$ & $\mathrm{E}-\mathrm{C}$ & 0.008 & 0.98 & 0.03 & 18.17 & 12.06 & 0.02 & 0.005 & 0.01 & - & $<0.01$ & FS13 & 9.1 \\
\hline $\mathrm{G}$ & E+Mo & 0.02 & 0.97 & 0.03 & 18.26 & 12.15 & 2.36 & 0.002 & 0.01 & - & $<0.01$ & $\mathrm{GS} 13$ & 11.8 \\
\hline $\mathrm{K}$ & E+Ni & 0.02 & 1 & 0.03 & 18.21 & 25.08 & 0.02 & $<0.001$ & 0.01 & - & $<0.01$ & KS13 & 9.6 \\
\hline $\mathrm{L}$ & E+Ni+Cr & 0.02 & 1.02 & 0.03 & 25.22 & 25.07 & 0.02 & $<0.001$ & 0.01 & - & $<0.01$ & LS13 & 9.1 \\
\hline $\mathrm{P}$ & E+Mo+Hf & 0.028 & 1.01 & 0.1 & 17.03 & 13.6 & 2.18 & - & - & 1.17 & 0.01 & PS15 & 9.6 \\
\hline B & Ind. 316 & 0.056 & 1.13 & 0.73 & 16.84 & 10.54 & 2.25 & 0.008 & 0.01 & - & 0.022 & BS13 & 5.5 \\
\hline
\end{tabular}

Note: Except for the industrial alloys with up to $0.29 \% \mathrm{Cu}, 0.22 \% \mathrm{Co}, 0.072 \% \mathrm{~N}$, and $0.022 \% \mathrm{~S}$, the others are reported with $<0.01 \% \mathrm{Cu}, 0.01 \% \mathrm{Co},<0.0005 \% \mathrm{~N}$, and $<0.007 \% \mathrm{~S}$. 
Table 3. Size $(\mathrm{nm})$ and density of Frank loops $\left(\times 10^{22} \mathrm{~m}^{-3}\right)$, cavities $\left(\times 10^{22} \mathrm{~m}^{-3}\right)$ and precipitates $\left(\times 10^{21} \mathrm{~m}^{-3}\right)$ observed in the irradiated samples.

\begin{tabular}{cccccccccc}
\hline \multirow{2}{*}{ Sample } & Dose & \multicolumn{2}{c}{ Frank Loops } & \multicolumn{2}{c}{ Cavities } & \multicolumn{2}{c}{ G-phase } & \multicolumn{2}{c}{ Unknown precipitates } \\
\cline { 2 - 9 } & dpa & Size (D) & Density (N) & Size (d) & Density (N) & Size (d) & Density (N) & Size (d) & Density (N) \\
\hline AS13 & 5.5 & $7.35 \pm 3.36$ & $10.6 \pm 1.21$ & $1.96 \pm 0.08$ & 0.801 & $4.85 \pm 0.88$ & 9.44 & $4.70 \pm 1.23$ & 2.99 \\
AS18 & 10.2 & $10.1 \pm 4.68$ & $8.46 \pm 0.71$ & $2.31 \pm 0.97$ & 3.28 & $3.55 \pm 0.50$ & 7.61 & & \\
BS13 & 5.5 & $8.00 \pm 4.31$ & $5.41 \pm 1.37$ & $2.73 \pm 0.62$ & 0.486 & $2.12 \pm 0.86^{*}$ & $21.3 \pm 4.25^{*}$ & & \\
BS16 & 10.2 & $9.18 \pm 4.20$ & $4.43 \pm 0.24$ & $4.34 \pm 1.14$ & 2.22 & $3.04 \pm 1.07^{*}$ & $6.84^{*}$ & $2.48 \pm 1.03$ & 33.9 \\
ES13 & 11.8 & $9.14 \pm 4.45$ & $2.56 \pm 0.43$ & - & - & $4.53 \pm 1.31$ & $8.84 \pm 0.25$ & 1.66 & 5.78 \\
FS13 & 9.1 & $6.36 \pm 3.46$ & $6.33 \pm 0.68$ & $2.28 \pm 0.95$ & 1.95 & & & $2.67 \pm 0.94$ & $13.9 \pm 0.98$ \\
GS13 & 11.8 & $8.53 \pm 3.74$ & $2.29 \pm 0.22$ & 9.93 & 0.027 & & & $2.05 \pm 0.92$ & $41.8 \pm 1.18$ \\
KS13 & 9.6 & $9.33 \pm 4.61$ & $4.82 \pm 0.68$ & $3.85 \pm 1.34$ & 0.173 & $4.66 \pm 0.69$ & 11.3 & $2.25 \pm 0.83$ & 12.1 \\
LS13 & 9.1 & $8.80 \pm 4.53$ & $5.13 \pm 0.36$ & - & - & $5.76 \pm 1.04$ & 8.65 & $3.05 \pm 1.25$ & 8.48 \\
PS15 & 9.6 & $8.38 \pm 4.16$ & $2.95 \pm 0.65$ & - & - & & & $2.20 \pm 0.64$ & 172 \\
SW37 & 4.4 & $5.92 \pm 3.57$ & $13.5 \pm 1.85$ & - & - & & & & \\
\hline
\end{tabular}

" $\gamma$ '-phase, rather than G-phase, in the BS13 and BS16.

Table 4. Fitting results of strength factor, $\alpha=\mathrm{k}_{1} \ln \left(\mathrm{k}_{2} d\right)$, for the obstacles presented in Fig. 2.

\begin{tabular}{ccccccc}
\hline \multirow{2}{*}{ Obstacles } & \multicolumn{2}{c}{ Fitting parameters } & Fit quality & $\begin{array}{c}\text { Volume } \\
\text { fraction }\end{array}$ & Core radius & Critical size \\
\cline { 2 - 7 } & $\mathrm{k}_{1}$ & $\mathrm{k}_{2}$ & $\mathrm{R}^{2}$ & $f, \%$ & $r_{0}, \mathrm{~nm}$ & $d, \mathrm{~nm}($ at $\alpha=0)$ \\
\hline Spherical ppts $\left(\alpha_{\mathrm{P}}\right)$ & 0.1757 & 2.7013 & 0.974 & 0.611 & $0.302(1.19 b)$ & 0.370 \\
Frank loops $\left(\alpha_{\mathrm{L}}\right)$ & 0.1969 & 1.4189 & 0.785 & $\mathrm{NA}^{*}$ & $0.449(1.77 b)$ & 0.705 \\
Cavities $\left(\alpha_{\mathrm{C}}\right)$ & 0.4654 & 0.9378 & 0.999 & 0.043 & $0.257(1.02 b)$ & 1.066 \\
\hline
\end{tabular}

$* \mathrm{NA}-$ not able to be deduced. 


\section{FIGURES}

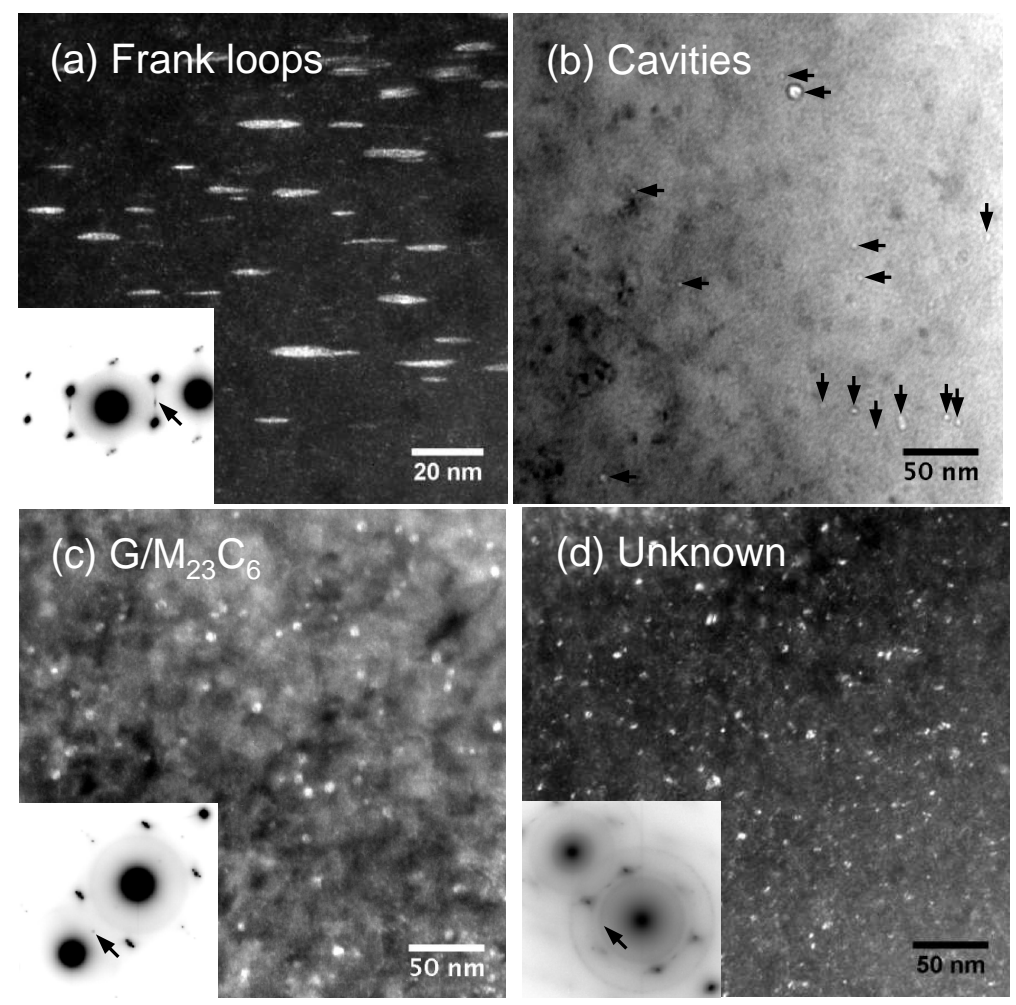

Fig. 1. Typical radiation-induced (a) Frank loops in sample BS13, (b) cavities in KS13, (c) $\mathrm{G} / \mathrm{M}_{23} \mathrm{C}_{6}$ precipitates in ES13, and (d) unkown precipitates in FS13. The arrow in each inset denotes the imaging condition for each DF image. 


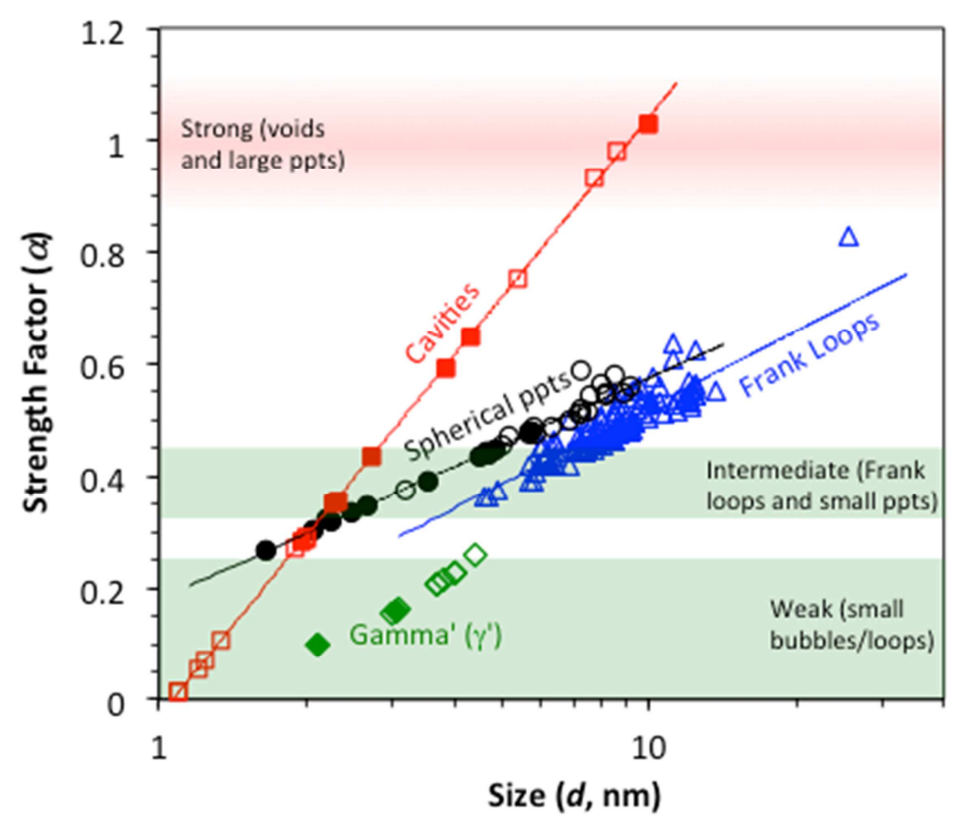

Fig. 2. Calculated size-dependent strength factor at room temperature for spherical precipitates (ppts, circles), coherent ppts (diamonds), Frank loops (triangles), and cavities (squares) from this work (solid symbols) and literature data (open symbols). The overlaid three shaded regimes are after [5].

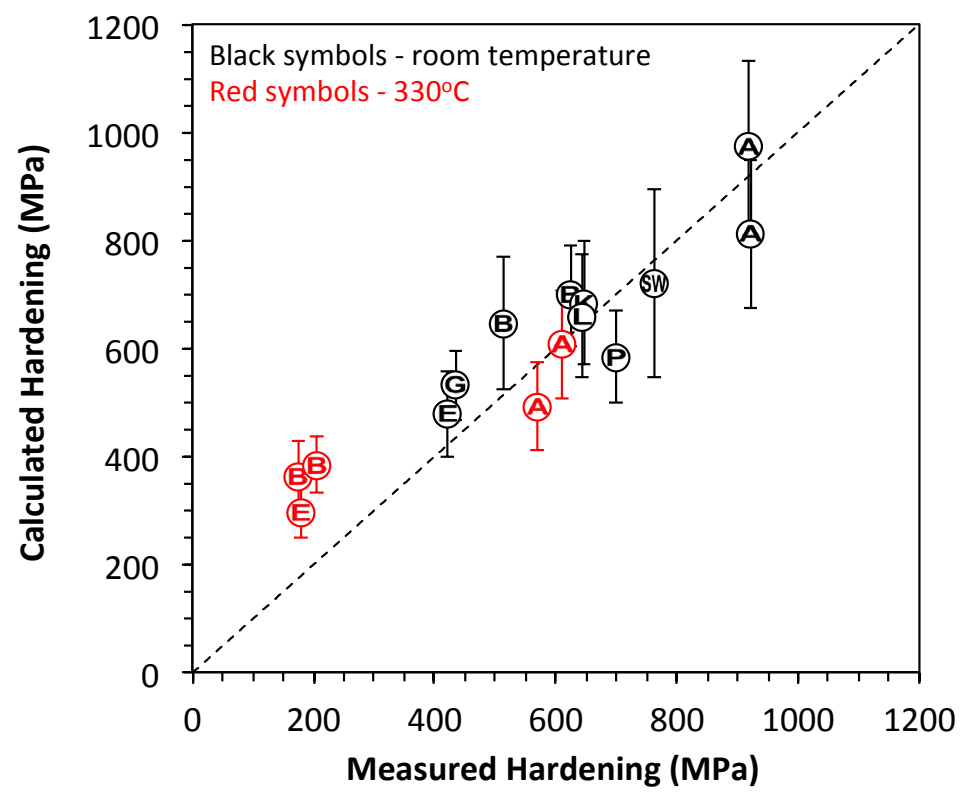

Fig. 3. Calculated radiation hardening compared with measured results of type 304 and 316 variants at room temperature and $330^{\circ} \mathrm{C}$. The enclosed letters denote the corresponding alloy samples. 